\title{
Diabetes Mellitus and Colorectal Neoplasia
}

\author{
Alejandro Acevedo ${ }^{1}$, Yaritza Diaz ${ }^{2}$, Cynthia M. Perez ${ }^{3}$, Maria Garau ${ }^{4}$ John Baron ${ }^{4}$, \\ Marcia Cruz-Correa ${ }^{1,2}$
}

${ }^{1}$ Department of Medicine, School of Medicine, University of Puerto Rico, San Juan, Puerto Rico; ${ }^{2}$ University of Puerto Rico Comprehensive Cancer Center, San Juan, Puerto Rico; ${ }^{3}$ Department of Biostatistics and Epidemiology, Graduate School of Public Health, Medical Sciences Campus, University of Puerto Rico, San Juan, Puerto Rico; ${ }^{4}$ Department of Medicine, Community and Family Medicine, Dartmouth Medical School, Hanover, USA.

Email: marcia.cruz1@upr.edu

Received August $9^{\text {th }}, 2012$; revised September $8^{\text {th }}, 2012$; accepted September $18^{\text {th }}, 2012$

\begin{abstract}
Background: Many studies have provided evidence for an association between obesity, physical inactivity, and western diet as risk factors for colorectal cancer (CRC). Few studies directly address the association between type 2 Diabetes Mellitus (DM) and the risk of colorectal lesions at specific anatomic locations. Methods: 2663 subjects with a previous history of adenoma(s) and removal of all current adenomas at study entry were followed for a mean time of three years across three different chemoprevention clinical trials. The primary endpoint was colorectal adenoma recurrence and number of lesions during the treatment phase; the secondary endpoints were presence of advanced colorectal neoplasia $(\mathrm{CRN})$ and location of CRN. Using log linear regression, the effect of DM status on the relative risk (RR) of CRN recurrence, advanced CRN, and location of CRN was assessed. Results: DM status was not significantly associated with incidence of colorectal adenomas, incidence of advanced colorectal lesions, or left-sided colorectal neoplastic lesions. Subjects with DM had a marginally increased risk of right-sided $(p=0.06)$ colorectal adenomas and a significant increased risk of multiple right-sided adenomas $(p=0.03)$ in the unadjusted model; this association was not significant after adjusting for age and other potential confounders $(\mathrm{RR}=1.22,95 \% \mathrm{CI}$ : $0.85-1.76)$. Conclusion: We did not observe a statistically significant increased risk in CRN recurrence for overall neoplasia, advanced neoplasia or location of neoplasia in individuals with DM compared to non-DM individuals. However, given the patterns observed in this investigation, future studies with longer follow-up time and longer DM exposure, incorporating objective measurements of type 2 DM might help elucidate the risk of CRN among individuals with DM.
\end{abstract}

Keywords: Diabetes Mellitus; Colorectal Neoplasia; Colorectal Adenomas; Chemoprevention

\section{Introduction}

Both abroad and in the United States (US), colorectal cancer (CRC) represents a major public health burden. Worldwide, an estimated 1.23 million new cases of CRC were diagnosed in 2008, making CRC the third most common cancer in men $(663,000$ or $10.0 \%$ of the total cases) and the second in women $(570,000$ or $9.4 \%$ of the total cases) [1]. As of January 1, 2007, in the US there were approximately 1,112,493 living men and women who had been diagnosed with $\mathrm{CRC}$ at some point in their lifetime [2].

Diabetes Mellitus (DM) affects approximately 194 million people worldwide [3]. More than 16 million people live with this condition in the US [4]. Various studies have provided evidence for an association between obesity and risk of CRC. Obesity, physical inactivity, and western diet have also been linked to type 2 DM [5]. Multiple studies have shown an association between type
$2 \mathrm{DM}$ and colorectal neoplasia (CRN), [4,6-8] while others have been inconclusive $[9,10]$. Moreover, data regarding the location of CRC lesions in individuals with type $2 \mathrm{DM}$ is lacking, with one study reporting a stronger association in the colon compared to the rectum [7].

Epidemiological studies have reported that type $2 \mathrm{DM}$ confers a $40 \%$ increased risk of colorectal neoplasia CRN [11]. Some investigators have hypothesized that hyperinsulinemia, which occurs early in the course of type $2 \mathrm{DM}$, is associated with a concomitant elevation in Insulin-Like Growth Factor (IGF) levels. Excess IGF levels and excess insulin levels exert a trophic effect on the gastrointestinal mucosa, and this in turn promotes the growth of colorectal tumors $[5,12]$.

The aim of this study was to investigate the association between type $2 \mathrm{DM}$ and risk of colorectal adenomas recurrence. Validation of type $2 \mathrm{DM}$ as a risk factor for recurrence of CRN may have important implications in our current prevention and control programs for CRC in 
individuals with type $2 \mathrm{DM}$. For instance, if type $2 \mathrm{DM}$ is found to be a risk factor for development of colorectal neoplasia, current $\mathrm{CRC}$ screening guidelines may require modification of the starting age and intervals of screening.

In the present investigation, we pooled data from three large multicenter large bowel adenoma chemoprevention trials to evaluate the association between DM and colorectal adenoma recurrence after adjusting for potential confounders. Specifically, we addressed whether a diagnosis of DM was associated with recurrence of overall colorectal neoplasia, advanced colorectal neoplasia and the location of colorectal neoplastic lesions.

\section{Methods}

The analysis was based on pooled data from three placebo-controlled, randomized colorectal adenoma chemoprevention trials: the Antioxidant Polyp Prevention Study [13], the Calcium Polyp Prevention Study [14], and the Aspirin/Folate Polyp Prevention Study [15], the details of which have been reported elsewhere. Written informed consent was obtained from each participant, and the institutional review board of every participating institution approved these studies.

Eligible subjects had at least one recently documented adenoma and underwent complete (to the cecum) colonoscopy at baseline with the endoscopist attesting that all polyps and areas suspicious for neoplasia were removed. Study subjects were not selected based on DM status; diagnosis of DM was determined on the basis of selfreport and use of oral hypoglycemic agents. Serologic testing for DM, age at diagnosis of DM, or duration of hypoglycemic agents were not recorded in any of the colorectal adenoma chemopreventive trials [13-15], thus was not available in the pooled database. Subjects were randomized to study agent or placebo with scheduled colonoscopic surveillance at 1 and 3 years after the qualifying examination in the antioxidant and calcium studies [13,14], and at 3 years in the aspirin study [15]. Treatment for all patients ended at the year 4 examination in the antioxidant and calcium studies, and at year 3 for the aspirin/folate study.

The estimated size and location of each colorectal lesion found during follow-up was recorded, and the polyps were removed and sent for central histologic review by a single study pathologist (D. C. Snover) [16]. For the present analysis, we used the diagnosis that occurred at the time of central review in each original study. We did not repeat the review of any pathology slides for this analysis.

Our primary endpoint was adenoma recurrence, defined as any colonic neoplastic lesions that occurred during the treatment phase of each trial, and which were measured in our analysis according to the follow-up colonoscopic examinations (year 4 for the antioxidant and calcium studies, year 3 for the aspirin study). We also considered the number of colorectal adenomas detected in follow-up and the location of CRN lesions. Lesions at or proximal to the splenic flexure were categorized as "right-sided" and those distal to the splenic flexure were classified as "left-sided." The secondary endpoint was the presence of advanced (CRN), defined as any lesion greater or equal than $1 \mathrm{~cm}$ in size and/or the presence of tubulovillous or villous histology and/or the presence of cancer.

At enrollment, participants were asked to complete a questionnaire addressing basic demographic characteristics, medical history (including height and weight), lifestyle factors, and usual diet (using a validated food frequency questionnaire). Demographic factors such as age, sex, and self-reported ethnicity and race were collected. Subjects were also asked about family history of CRC and polyps. Smoking status was categorized as never, former, and current users. Alcohol was categorized by number of daily drinks. Body mass index (BMI) was calculated from baseline information on height and weight and divided into three categories: normal $(<25.0$ $\left.\mathrm{kg} / \mathrm{m}^{2}\right)$, overweight $\left(25.0-29.9 \mathrm{~kg} / \mathrm{m}^{2}\right)$, and obese $(\geq$ $30.0 \mathrm{~kg} / \mathrm{m}^{2}$ ).

Dietary patterns were evaluated at baseline with a self-administered semi-quantitative food frequency questionnaire, initially developed by the National Cancer Institute and now maintained by Nutrition Quest [17] that has been previously validated by others [18-20]. The surveys requested information about usual diet over the previous year and included approximately 100 food items (plus open-ended questions for frequent eaten, unlisted foods). In the first two studies, the original questionnaire was used [17]. An updated version was used for the aspirin study [18]. This instrument was used to record intake of carbohydrates, fat (all and saturated), protein, fiber, meat (red, processed), and calcium intake, among others.

From the pooled studies, data was available for analysis from a total of 2915 participants with study endpoints; however, information on follow-up colonoscopy was not available in 248, and DM status was not available in 4 individuals. After excluding participants who did not meet the specified criteria, the final study population consisted of 2663 subjects (787 males and 1876 females).

Statistical Analysis. Univariate analysis was done to characterize the study population in terms of sociodemographic and clinical criteria. Chi-square tests or Fisher's exact test for categorical variables and Student's $\mathrm{t}$ test for quantitative variables were used to assess comparability between groups. Log-linear regression for binary data was used to assess the effect of DM status on 
the relative risk (RR) of colorectal adenoma recurrence, advanced colorectal adenoma, and left-sided and rightsided colorectal neoplastic lesions. Ordinal logistic regression was fit to assess the effect of DM status on the number of total, left-sided and right-sided adenomas (i.e., $0,1, \geq 2$ ). The satisfaction of the proportionality-of-odds assumption (association between DM status and the odds of increased adenomas is constant regardless of the cutoff used to classify the outcome) was assessed with the likelihood ratio test. Covariates found to be statistically significant $(\mathrm{p}<0.05)$ between subjects with and without DM (Table 2) on bivariate analysis and those deemed scientifically important and selected a priori were included in the multivariate logistic model. These variables included age at study entry, sex, education, BMI (normal, overweight, obese), smoking status, alcohol consumption (drinks/day), total fat consumption (g/day), red meat consumption ( $\mathrm{g} /$ day), dietary fiber ( $\mathrm{g} /$ day), family history of CRC, (defined as a first-degree relative diagnosed with CRC), chemoprevention trial number $(1,2,3)$ and treatment assignment (placebo, treatment). Data manage- ment and analyses were performed using the statistical package Stata (Version 10.0, College Station, TX).

\section{Results}

Baseline characteristics. Of the 2915 subjects, 2663 subjects $(91.4 \%)$ had complete information (baseline and follow up colonoscopies and DM status) and were included in this analysis. A total of 1690 subjects were assigned to active arms, while 973 subjects were assigned to placebo (Table 1).

There were a total of 747 participants included in the Antioxidant Polyp Prevention Study [13], 832 participants in the Calcium Polyp Prevention Study [14], and 1084 participants in the Aspirin/Folate Polyp Prevention Study [15] (Table 1).

Comparison of baseline characteristics according to DM status is presented in Table 2. Subjects with diabetes were significantly $(\mathrm{p}<0.05)$ older, less likely to have a high school diploma, less likely to drink alcohol, more likely to be obese and more likely to consume dietary fiber.

Table 1. Baseline characteristics ${ }^{\mathrm{a}}$ of study participants in the Polyp Prevention Studies $(\mathrm{n}=\mathbf{2 6 6 3})$.

\begin{tabular}{|c|c|c|c|}
\hline Characteristic & $\begin{array}{c}\text { Antioxidant Polyp Prevention } \\
\text { Study }(\mathrm{n}=747)\end{array}$ & $\begin{array}{l}\text { Calcium Polyp Prevention Study } \\
\qquad(\mathrm{n}=832)\end{array}$ & $\begin{array}{l}\text { Aspirin/Folate Polyp Prevention } \\
\text { Study }(\mathrm{n}=1084)\end{array}$ \\
\hline Median age, yr & $62(56,66)$ & $62(55,67)$ & $57(51,64)$ \\
\hline Female sex, n (\%) & $588(78.7)$ & $598(71.9)$ & $690(63.7)$ \\
\hline \multicolumn{4}{|l|}{ Race, n (\%) } \\
\hline White & $638(85.4)$ & $710(85.3)$ & $928(85.6)$ \\
\hline Black & $52(7.0)$ & $65(7.8)$ & $63(5.8)$ \\
\hline Other & $57(7.6)$ & $57(6.9)$ & $93(8.6)$ \\
\hline \multicolumn{4}{|l|}{ Highest educational level, n (\%) } \\
\hline$<12$ years & $153(20.5)$ & $164(19.7)$ & $107(9.9)$ \\
\hline$\geq 12$ years & $594(79.5)$ & $667(80.3)$ & $977(90.1)$ \\
\hline \multicolumn{4}{|l|}{ Smoking status, $\mathrm{n}(\%)$} \\
\hline Never & $240(32.8)$ & $288(34.6)$ & $462(42.7)$ \\
\hline Former & $352(48.1)$ & $398(47.8)$ & $462(42.7)$ \\
\hline Current & $140(19.1)$ & $146(17.6)$ & $157(14.5)$ \\
\hline Median alcohol intake, drinks/day & $0.2(0,1.0)$ & $0.1(0,0.8)$ & $0.1(0,0.9)$ \\
\hline \multicolumn{4}{|l|}{ BMI $\left(\mathrm{kg} / \mathrm{m}^{2}\right), \mathrm{n}(\%)$} \\
\hline$<25.0$ & $233(31.4)$ & $258(31.1)$ & $333(30.8)$ \\
\hline $25.0-29.9$ & $363(48.9)$ & $366(44.1)$ & $507(46.9)$ \\
\hline$\geq 30.0$ & $147(19.7)$ & $206(24.8)$ & $242(22.3)$ \\
\hline DM diagnosis, n (\%) & $43(5.8)$ & $77(9.3)$ & $65(6.0)$ \\
\hline Cancer diagnosis, n (\%) & $72(9.6)$ & $68(8.2)$ & $71(6.6)$ \\
\hline CRC family history, $\mathrm{n}(\%)$ & $150(20.5)$ & $191(23.9)$ & $332(37.3)$ \\
\hline Median total fat intake, g/day & $79.1(56.4,107.6)$ & $80.2(55.1,109.3)$ & $58.7(39.9,80.9)$ \\
\hline Median red meat intake, servings/day & $0.5(0.2,0.7)$ & $0.4(0.2,0.7)$ & $0.3(0.1,0.5)$ \\
\hline Median fiber intake, $\mathrm{g} /$ day & $12.7(9.6,17.8)$ & $15.0(11.3,20.3)$ & $12.1(8.9,16.7)$ \\
\hline
\end{tabular}

${ }^{\mathrm{a}}$ Data are expressed as median (percentiles 25 and 75 ) and percentages. 
Table 2. Baseline characteristics of study participants according to DM status ${ }^{\mathrm{a}}(\mathrm{n}=\mathbf{2 6 6 3})$.

\begin{tabular}{|c|c|c|c|}
\hline Characteristic & $D M+$ & $D M-$ & $\mathrm{p}$ value \\
\hline Median age, yr & $64(58,68)$ & $60(53,66)$ & $<0.001$ \\
\hline Female sex, n (\%) & $142(76.8)$ & $1734(70.0)$ & 0.05 \\
\hline \multicolumn{4}{|l|}{ Race, n (\%) } \\
\hline White & $152(82.2)$ & $2124(85.7)$ & \multirow{3}{*}{0.34} \\
\hline Black & $17(9.2)$ & $163(6.6)$ & \\
\hline Other & $16(8.6)$ & $191(7.7)$ & \\
\hline \multicolumn{4}{|l|}{ Highest educational level, n (\%) } \\
\hline$<12$ years & $55(29.7)$ & $369(14.9)$ & \multirow[t]{2}{*}{$<0.001$} \\
\hline$\geq 12$ years & $130(70.3)$ & $2108(85.1)$ & \\
\hline \multicolumn{4}{|l|}{ Smoking, n (\%) } \\
\hline Never & $77(41.9)$ & $913(37.1)$ & \multirow{3}{*}{0.43} \\
\hline Former & $79(42.9)$ & $1133(46.0)$ & \\
\hline Current & $28(15.2)$ & $415(16.9)$ & \\
\hline Median alcohol intake drinks/day & $0(0,0.3)$ & $0.2(0,1.0)$ & $<0.001$ \\
\hline \multicolumn{4}{|l|}{ BMI $\left(\mathrm{kg} / \mathrm{m}^{2}\right), \mathrm{n}(\%)$} \\
\hline$<25.0$ & $34(18.4)$ & $790(32.0)$ & \\
\hline $25.0-29.9$ & $84(45.4)$ & $1152(46.6)$ & \\
\hline$\geq 30.0$ & $67(36.2)$ & $528(21.4)$ & $<0.001$ \\
\hline Personal cancer history, n (\%) & $14(7.6)$ & $197(8.0)$ & 0.85 \\
\hline Family history of CRC, n (\%) & $37(22.4)$ & $636(28.2)$ & 0.11 \\
\hline Median total fat intake, $g$ /day & $71.2(45.5,102.9)$ & $70.5(48.5,98.4)$ & 0.71 \\
\hline Median red meat intake, servings/day & $0.3(0.2,0.7)$ & $0.4(0.2,0.6)$ & 0.26 \\
\hline Median fiber intake, $g /$ day & $14.1(10.9,19.4)$ & $13.3(9.7,18.0)$ & 0.015 \\
\hline
\end{tabular}

${ }^{a}$ Data are expressed as median (percentiles 25 and 75 ) and percentages.

CRN Recurrence. Among the subjects included in our study, 1,034 (38.8\%) had at least one colorectal neoplastic lesion detected at follow up; $580(21.8 \%)$ had at least one left-sided lesion, and $650(24.4 \%)$ had at least one right-sided lesion. There were $250(9.4 \%)$ subjects with at least one advanced colonic neoplastic lesion $(\geq 1 \mathrm{~cm}$ in size and/or the presence of tubulovillous or villous histology and/or the presence of cancer); 106 (4\%) subjects had left-sided advanced adenomas and $150(5.6 \%)$ had right-sided advanced adenomas. Twelve $(0.4 \%)$ subjects developed CRC.

CRN Recurrence According to DM Status. Data on recurrence of CRN according to DM status for the complete cohort is presented in Table 3 . Within the DM group, $43.8 \%$ of subjects developed at least one adenoma, compared to $38.5 \%$ in the non-DM group ( $\mathrm{RR}=1.25$, $95 \%$ CI: $0.92-1.68$ ). Similarly, $24.9 \%$ and $30.3 \%$ of DM subjects developed at least one left- and right-sided adenoma, respectively, compared to $21.6 \%$ and $24.0 \%$ in the non-DM group. Subjects with DM had a marginally $(\mathrm{p}=$ 0.06 ) increased risk of right-sided colorectal adenomas in the unadjusted model. However, after adjusting for age and other potential confounders, the association between DM status and right-sided colorectal adenomas was not statistically significant (age adjusted $\mathrm{RR}=1.31,95 \% \mathrm{CI}$ : $0.94-1.81$; multivariate-adjusted $\mathrm{RR}=1.22,95 \% \mathrm{CI}$ : $0.85-1.76)$. DM status was not significantly associated with the overall incidence of colorectal adenomas or the incidence of left colorectal lesions (Table 3).

Evaluation of multiple adenomas is presented in Table 3. Within the DM group, 7.6\% (15) of subjects developed $\geq 2$ left-sided adenomas, compared to $6.3 \%$ (157) in the non-DM group $(\mathrm{p}=0.29)$. Among the DM group, $13.5 \%$ (35) of subjects developed $\geq 2$-right-sided adenomas, compared to $8.5 \%$ (210) in the non-DM group (unadjusted $\mathrm{RR}=1.42,95 \%$ CI $1.03-1.96$; age adjusted $\mathrm{RR}=1.33,95 \%$ CI: $0.96-1.84)$.

Advanced CRN. There were 19 (10.3\%) subjects within the DM group who developed at least one advanced adenoma compared to $231(9.3 \%)$ in the non- DM group (Table 3). DM status was not significantly associated with advanced neoplasia in the unadjusted or adjusted models. When these analyses were repeated for those individuals randomized to the placebo arm $(\mathrm{n}=$ 
Table 3. Adjusted relative risks and $95 \%$ confidence intervals for any colorectal adenoma according to $\mathrm{DM}$ status $(\mathrm{n}=\mathbf{2 6 6 3})$.

\begin{tabular}{|c|c|c|c|c|c|}
\hline Outcome & $\begin{array}{c}\mathrm{DM}+ \\
(\%)\end{array}$ & $\begin{array}{c}\text { DM - } \\
(\%)\end{array}$ & $\begin{array}{l}\text { Unadjusted RR } \\
(95 \% \mathrm{CI})\end{array}$ & $\begin{array}{l}\text { Age-adjusted RR } \\
\text { (95\% CI) }\end{array}$ & $\begin{array}{c}\text { Multivariate-adjusted } R^{\mathrm{a}} \\
(95 \% \mathrm{CI})\end{array}$ \\
\hline Total adenoma & $81(43.8)$ & $953(38.5)$ & $\begin{array}{c}1.25(0.92-1.68) \\
p=0.15\end{array}$ & $\begin{array}{c}1.17(0.86-1.58) \\
\mathrm{p}=0.32\end{array}$ & $\begin{array}{c}1.16(0.83-1.63) \\
\mathrm{p}=0.39\end{array}$ \\
\hline Left adenoma & $46(24.9)$ & $534(21.6)$ & $\begin{array}{c}1.20(0.85-1.70) \\
p=0.29\end{array}$ & $\begin{array}{c}1.13(0.80-1.60) \\
\mathrm{p}=0.50\end{array}$ & $\begin{array}{c}1.18(0.80-1.74) \\
\mathrm{p}=0.39\end{array}$ \\
\hline Right adenoma & $56(30.3)$ & $594(24.0)$ & $\begin{array}{c}1.38(0.99-1.91) \\
\mathrm{p}=.055\end{array}$ & $\begin{array}{c}1.31(0.94-1.81) \\
\mathrm{p}=0.11\end{array}$ & $\begin{array}{c}1.22(0.85-1.76) \\
p=0.29\end{array}$ \\
\hline $\begin{array}{c}\text { Number of left adenoma } \\
0 \\
1 \\
\geq 2\end{array}$ & $\begin{array}{c}139(75.1) \\
32(17.3) \\
15(7.6)\end{array}$ & $\begin{array}{c}1944(78.5) \\
377(15.2) \\
157(6.3)\end{array}$ & $\begin{array}{c}1.21(0.85-1.70) \\
\mathrm{p}=0.29\end{array}$ & $\begin{array}{c}1.13(0.80-1.59) \\
\mathrm{p}=0.50\end{array}$ & $\begin{array}{c}1.17(0.80-1.72) \\
\quad \mathrm{p}=0.41\end{array}$ \\
\hline $\begin{array}{c}\text { Number of right adenom } \\
0 \\
1 \\
\geq 2\end{array}$ & $\begin{array}{l}129(69.7) \\
31(16.8) \\
25(13.5)\end{array}$ & $\begin{array}{c}1884(76.0) \\
384(15.5) \\
210(8.5)\end{array}$ & $\begin{array}{c}1.42(1.03-1.96) \\
p=0.03\end{array}$ & $\begin{array}{c}1.33(0.96-1.84) \\
\mathrm{p}=0.09\end{array}$ & $\begin{array}{c}1.22(0.85-1.75) \\
p=0.28\end{array}$ \\
\hline Advanced adenoma & $19(10.3)$ & $231(9.3)$ & $\begin{array}{c}1.11(0.68-1.82) \\
\mathrm{p}=0.67\end{array}$ & $\begin{array}{c}1.03(0.62-1.68) \\
\mathrm{p}=0.92\end{array}$ & $\begin{array}{c}0.82(0.45-1.49) \\
\mathrm{p}=0.51\end{array}$ \\
\hline
\end{tabular}

${ }^{a}$ Adjusted for age, sex, educational level, BMI, smoking status, alcohol consumption, family history of CRC, total fat consumption, dietary fiber consumption, red meat consumption, study number and trial treatment assignment. ${ }^{b}$ Number of adenomas was analyzed by ordinal logistic regression analysis assuming the proportional odds assumption (i.e., same regression coefficients for all outcome categories). The odds ratio can be interpreted as constant across all possible outcome categories.

973), no significant differences with regards to overall neoplasia recurrence rate, advanced neoplasia, or location of neoplasia were observed (data not shown).

\section{Discussion}

The initial stages of DM are characterized by elevated levels of IGF's as well as by hyperinsulinemia. Excess IGF levels (as well as insulin) may exert trophic effects on the colonic mucosa by decreasing apoptosis, leading to an increased risk of developing CRN [21]. In this pooled analysis of three randomized clinical trials, we observed that individuals with DM had a similar risk for $\mathrm{CRN}$ recurrence compared to non-DM individuals. Although there was a statistically significant association between DM and the risk for right-sided colorectal adenomas, the association was no longer significant after controlling for age at study entry, sex, education, BMI, smoking status, alcohol consumption, total fat consumption, red meat consumption, dietary fiber, family history of $\mathrm{CRC}$, chemoprevention trial number and treatment assignment.

Individuals with DM did not have a statistically significant increased risk of developing advanced CRN or left-sided CRN compared to individuals without DM. Our findings provide only weak support for previous epidemiological studies reporting an increased risk of CRN among individuals with DM [4,6-8]. In a study by Yang and colleagues in the United Kingdom, it was found that people with type $2 \mathrm{DM}$ had $42 \%(95 \% \mathrm{CI}$ : $25 \%-62 \%$ ) higher risk of developing CRC compared to people without type $2 \mathrm{DM}$ [8]. A meta-analysis by Larsson and colleagues (2005) about the association between CRC and DM found that people with DM had 30\% (95\% CI: $20 \%-40 \%$ ) higher risk of developing CRC compared to people without DM [7]. In addition, there was a significant association between DM and cancer subsite $($ colon $\mathrm{RR}=1.43 ; 95 \% \mathrm{CI}: 1.28-1.60$ and rectum $\mathrm{RR}=$ 1.33; 95\% CI: 1.14 - 1.54) [7].

In an investigation by Campbell and colleagues (2010) using the Cancer Prevention Study II Nutrition Cohort, it was observed that men with type 2 DM had a $24 \%$ higher risk of developing CRC compared to men without type 2 DM [6]. However, they did not observe an association between type $2 \mathrm{DM}$ and $\mathrm{CRC}$ among women $(\mathrm{RR}=1.01$; 95\% CI: 0.82 - 1.23). Limburg and colleagues reported that men with type $2 \mathrm{DM}$ had $96 \%$ higher risk of proximal colon cancer compared to men without type 2 DM [4] (95\% CI: 1.16 - 3.10); but an increased risk for distal colon cancer was not observed (SIR $=1.43 ; 95 \% \mathrm{CI}$ : 0.82 - 2.32). However, the investigators did not observe a significant association between type $2 \mathrm{DM}$ and proximal colon cancer (SIR $=1.17 ; 95 \%$ CI: $0.58-2.09$ ) among women.

Significant differences in selected dietary and lifestyle were observed between patients with and without DM. Individuals with DM in our cohort were more likely to be overweight or obese and eat processed meats, compared to non-DM individuals. Previous investigations have shown that obesity is a risk factor for development of CRN [5], with excess risk among individuals with BMI $\geq$ 
$30.0 \mathrm{~kg} / \mathrm{m}^{2}$. In a study by Elwing and colleagues (2006), it was found that obese people with type $2 \mathrm{DM}$ had higher rates of colorectal adenomas ( $42 \%$ vs. $23 \%$; p < 0.001 ) compared to non-obese and non-DM people [22]. Similarly, diets high in processed meat protein and fats have been found to increase the risk of CRN through several mechanisms. Perhaps some of the increased risk for CRN observed among individuals with DM might be related to other coexisting exposures/diseases such as diet and/or obesity, or it may be multi-factorial.

Our study has several strengths that maximize our ability to explore the relationship between DM and the risk of CRN including: similarities in the design of the methodology between the parent studies, the protocolspecified procedures for surveillance colonoscopy, and the availability of complete data for characteristics of incident colorectal neoplasia, including size, number, and histology. Furthermore, the large sample size permitted stratification of the analyses by the aforementioned variables, and also allowed for exploratory analyses based on the association between DM and recurrence of CRN.

Nonetheless, there are several limitations that need to be addressed. First, our study included a relatively short follow-up time (approximately 3 years) of observation after baseline colonoscopy and polypectomy; however, this follow-up time has been shown to be adequate for assessing recurrence of CRN in several colorectal neoplastic chemo-preventive agents [23,24]. Second, we used self-reported information to classify cases of DM, thus non-differential misclassification of DM status may be present, although this is likely to have been minimal. Serologic confirmation of DM and specific treatment regimens for DM were not available in the database, which limited our ability to examine DM treatment regimens. Third, we were unable to distinguish subjects with type 1 and type $2 \mathrm{DM}$; however, most individuals of the cohorts were over 50 years of age and thus more likely to have had type $2 \mathrm{DM}$. Finally, the small number of DM subjects might have limited our ability to detect smaller but potentially clinically significant associations between DM status and overall and/or advanced colorectal.

In summary, we did not observe a statistically significant increased risk in CRN recurrence for overall neoplasia, advanced neoplasia or location of neoplasia in individuals with DM when compared to non-DM individuals. However, given the patterns observed in this investigation, future studies with longer follow-up time and longer DM exposure, incorporating objective measurements of type 2 DM (insulin levels, glucose, and C-peptide) might help elucidate the risk of CRN among individuals with DM.

\section{Acknowledgements}

This publication was possible by grants R25 RR 017589 and 1U54RR026139-01A1 from the National Center for
Research Resources; by grants 8U54MD 007587-03 from the National Institute on Minority Health and Health Disparities; and by grants K22 CA115913, CA059005, CA046927, CA37287, and CA23108 from the National Cancer Institute (NCI). Its contents are solely the responsibility of authors and do not necessarily represent the official view of the National Institutes of Health.

\section{REFERENCES}

[1] A. Jemal, R. Siegel, J. Xu and E. Ward, "Cancer Statistics," 2010. CA: A Cancer Journal for Clinicians, Vol. 60, 5, No. 22010, pp. 77-300. doi:10.3322/caac.20073

[2] J. E. Shaw, R. A. Sicree and P. Z. Zimmet, "Global Estimates of the Prevalence of Diabetes for 2010 and 2030," Diabetes Research and Clinical Practice, Vol. 87, No. 1, 2010, pp. 4-14. doi:10.1016/j.diabres.2009.10.007

[3] National Diabetes Fact Sheet, "General Information and National Estimates on Diabetes in the United States, 2007," In: G. A. Atlanta, Ed., Centers for Disease Control and Prevention, US Department of Health and $\mathrm{Hu}-$ man Services, 2008.

[4] P. J. Limburg, R. A. Vierkant, Z. S. Fredericksen, C. L. Leibson, R. A. Rizza, A. K. Gupta, D. A. Ahlquist, L. J. Melton 3rd, T. A. Sellers and J. R. Cerhan, "Clinically Confirmed Type 2 Diabetes Mellitus and Colorectal Cancer Risk: A Population-Based, Retrospective Cohort Study," The American Journal of Gastroenterology, Vol. 101, No. 8, 2006, pp. 1872-1879. doi:10.1111/j.1572-0241.2006.00725.x

[5] T. I. Nilsen and L. J. Vatten, "Prospective Study of Colorectal Cancer Risk and Physical Activity, Diabetes, Blood Glucose and BMI: Exploring the Hyperinsulinaemia Hypothesis," British Journal of Cancer, Vol. 84, No. 3, 2001, pp. 417-422. doi:10.1054/bjoc.2000.1582

[6] P. T. Campbell, A. Deka, E. J. Jacobs, C. C. Newton, J. S. Hildebrand, M. L. McCullough, P. J. Limburg and S. M. Gapstur, "Prospective Study Reveals Associations Between Colorectal Cancer and Type 2 Diabetes Mellitus or Insulin Use in Men," Gastroenterology, Vol. 139, No. 4, 2010, pp. 1138-1146. doi:10.1053/j.gastro.2010.06.072

[7] S. C. Larsson, N. Orsini and A. Wolk, "Diabetes Mellitus and Risk of Colorectal Cancer: A Meta-Analysis," Journal of the National Cancer Institute, Vol. 97, No. 22, 2005, pp. 1679-1687. doi:10.1093/jnci/dji375

[8] Y. X. Yang, S. Hennessy and J. D. Lewis, "Type 2 Diabetes Mellitus and the Risk of Colorectal Cancer," Clinical Gastroenterology and Hepatology: The Official Clinical Practice Journal of the American Gastroenterological Association, Vol. 3, No. 6, 2005, pp. 587-594.

[9] K. T. Khaw, N. Wareham, S. Bingham, R. Luben, A. Welch and N. Day, "Preliminary Communication: Glycated Hemoglobin, Diabetes, and Incident Colorectal Cancer in Men and Women: A Prospective Analysis From the European Prospective Investigation into Cancer-Norfolk Study," Cancer Epidemiology, Biomarkers \& Prevention: A Publication of the American Association for Cancer Research, Cosponsored by the American So- 
ciety of Preventive Oncology, Vol. 13, No. 6, 2004, pp. 915-919.

[10] P. J. Limburg, K. E. Anderson, T. W. Johnson, D. R. Jacobs Jr., D. Lazovich, C. P. Hong, K. K. Nicodemus and A. R. Folsom, "Diabetes Mellitus and Subsite-Specific Colorectal Cancer Risks in the Iowa Women's Health Study," Cancer epidemiology, Biomarkers \& Prevention: A Publication of the American Association for Cancer Research, Cosponsored by the American Society of Preventive Oncology, Vol. 14, No. 1, 2005, pp. 133-137.

[11] L. Le Marchand, L. R. Wilkens, L. N. Kolonel, J. H. Hankin and L. C. Lyu, "Associations of Sedentary Lifestyle, Obesity, Smoking, Alcohol Use, and Diabetes with the Risk of Colorectal Cancer," Cancer Research, Vol. 57, No. 21, 1997, pp. 4787-4794.

[12] K. Bowers, D. Albanes, P. Limburg, P. Pietinen, P. R. Taylor, J. Virtamo and R. Stolzenberg-Solomon, "A Prospective Study of Anthropometric and Clinical Measurements Associated with Insulin Resistance Syndrome and Colorectal Cancer in Male Smokers," American Journal of Epidemiology, Vol. 164, No. 7, 2006, pp. 652-664. doi:10.1093/aje/kwj253

[13] E. R. Greenberg, J. A. Baron, T. D. Tosteson, D. H. Freeman Jr., G. J. Beck, J. H. Bond, T. A. Colacchio, J. A .Coller, H. D. Frankl, R. W. Haile, et al., "A Clinical Trial of Antioxidant Vitamins To Prevent Colorectal Adenoma. Polyp Prevention Study Group," The New England Journal of Medicine, Vol. 331, No. 3, 1994, pp. 141-147. doi:10.1056/NEJM199407213310301

[14] J. A. Baron, M. Beach, J. S. Mandel, R. U. van Stolk, R. W. Haile, R. S. Sandler, R. Rothstein, R. W. Summers, D. C. Snover, G. J. Beck, et al., "Calcium Supplements for the Prevention of Colorectal Adenomas. Calcium Polyp Prevention Study Group," The New England Journal of Medicine, Vol. 340, No. 2, 1999, pp. 101-107. doi:10.1056/NEJM199901143400204

[15] J. A. Baron, B. F. Cole, R. S. Sandler, R. W. Haile, D. Ahnen, R. Bresalier, G. McKeown-Eyssen, R.W. Summers, R. Rothstein, C. A. Burke, et al., "A Randomized Trial of Aspirin to Prevent Colorectal Adenomas," The New England Journal of Medicine, Vol. 348, No. 10, 2003, 891-899. doi:10.1056/NEJMoa021735

[16] E. Torlakovic, E. Skovlund, D. C. Snover, G. Torlakovic and J. M. Nesland, "Morphologic Reappraisal of Serrated Colorectal Polyps," The American Journal of Surgical Pathology, Vol. 27, No. 1, 2003, pp. 65-81. doi:10.1097/00000478-200301000-00008

[17] G. Block, A. M. Hartman, C. M. Dresser, M. D. Carroll, J. Gannon and L. Gardner, "A Data-Based Approach to Diet Questionnaire Design and Testing," American Journal of Epidemiology, Vol. 124, No. 3, 1986, pp. 453-469.

[18] G. Block, M. Woods, A. Potosky and C. Clifford, "Validation of A Self-Administered Diet History Questionnaire Using Multiple Diet Records," Journal of Clinical Epidemiology, Vol. 43, No. 12, 1990, pp. 1327-1335. doi:10.1016/0895-4356(90)90099-B

[19] J. Sobell, G. Block, P. Koslowe, J. Tobin and R. Andres, "Validation of a Retrospective Questionnaire Assessing Diet 10-15 Years Ago," American Journal of Epidemiology, Vol. 130, No. 1, 1989, pp. 173-187.

[20] A. F. Subar, F. E. Thompson, V. Kipnis, D. Midthune, P. Hurwitz, S. McNutt, A. McIntosh and S. Rosenfeld, "Comparative Validation of the Block, Willett, and National Cancer Institute food frequency questionnaires: The Eating at America's Table Study," American Journal of Epidemiology, Vol. 154, No. 12, 2001, pp. 1089-1099. doi:10.1093/aje/154.12.1089

[21] V. A. Ezzat, E. R. Duncan, S. B. Wheatcroft and M. T. Kearney, "The Role of IGF-I and Its Binding Proteins in the Development of Type 2 Diabetes and Cardiovascular Disease," Diabetes, Obesity and Metabolism, Vol. 10, No. 3, 2008, pp. 198-211. doi:10.1111/j.1463-1326.2007.00709.x

[22] J. E. Elwing, F. Gao, N. O. Davidson and D. S. Early, "Type 2 Diabetes Mellitus: The Impact on Colorectal Adenoma Risk in Women," The American Journal of Gastroenterology, Vol. 101, No. 8, 2006, pp. 1866-1871. doi:10.1111/j.1572-0241.2006.00651.x

[23] J. A. Baron, M. Beach, J. S. Mandel, R. U. van Stolk, R. W. Haile, R. S. Sandler, R. Rothstein, R. W. Summers, D. C. Snover, G. J. Beck, et al., "Calcium Supplements and Colorectal Adenomas. Polyp Prevention Study Group," Annals of the New York Academy of Sciences, Vol. 889, 1999, pp. 138-145. doi:10.1111/j.1749-6632.1999.tb08731.x

[24] R. S. Sandler, S. Halabi, J. A. Baron, S. Budinger, E. Paskett, R. Keresztes, N. Petrelli, J. M. Pipas, D. D. Karp, C. L. Loprinzi, et al., "A Randomized Trial of Aspirin to Prevent Colorectal Adenomas in Patients with Previous Colorectal Cancer," The New England Journal of Medicine, Vol. 348, No. 10, 2003, pp. 883-890.

doi:10.1056/NEJMoa021633 